\title{
Ethylmalonic-Adipic Aciduria
}

\author{
IN VIVO AND IN VITRO STUDIES INDICATING DEFICIENCY
}

\author{
OF ACTIVITIES OF MULTIPLE ACYL-CoA DEHYDROGENASES
}

\author{
Stephanos Mantagos, Myron Genel, and Kay Tanaka, Departments of \\ Human Genetics and Pediatrics, Yale University School of Medicine, \\ New Haven, Connecticut 06510
}

A B STRACT The mechanisms underlying ethylmalonic-adipic aciduria were studied in a 5-yr-old girl. Oxidation of radioactive substrates by cultured skin fibroblasts from the proband and asymptomatic family members was also determined and compared to that by normal fibroblasts and that by cells from a patient with glutaric aciduria type II.

Feeding medium-chain triglycerides promptly induced vomiting and lethargy accompanied by a pronounced increase of urinary ethylmalonate. Significant increases of serum isovalerate and urinary isovalerylglycine were observed after leucine feeding, but urinary glutarate increased only slightly after lysine feeding. Thus, the results from clinical investigation remained equivocal as to whether pathways other than fatty acid oxidation were blocked in our patient.

Oxidation of $\left[1-{ }^{14} \mathrm{C}\right]$ butyrate by cultured skin fibroblasts from the proband was reduced to $14 \%$ of control. In vitro oxidation of $\left[2-{ }^{14} \mathrm{C}\right]$ lysine and $\left[2-{ }^{14} \mathrm{C}\right]$ leucine was also reduced to 28 and $23 \%$ of control, respectively. Much more severe reduction in oxidation of these three substrates $(3,9$, and $9 \%$, respectively) was observed in glutaric aciduria type II cells.

These results indicated that in the proband, degradative pathways of fatty acids, lysine, and leucine are blocked at the steps of butyryl-CoA, glutaryl-CoA, and isovaleryl-CoA dehydrogenases, respectively, as in the

A portion of this work has appeared in abstract form in 1978. Pediatr. Res. 12: 453.

Dr. Mantagos was a Postdoctoral Fellow in Human Genetics supported by grant HD-00198 from the National Institutes of Health; his present address is Department of Pediatrics, Division of Medical Genetics, Nassau County Medical Center, East Meadow, N. Y. 11554. Address reprint requests to Dr. Kay Tanaka, Department of Human Genetics, Yale University School of Medicine, New Haven, Conn. 06510.

Received for publication 19 April 1979 and in revised form 26 July 1979. case of glutaric aciduria type II. Because activities of multiple acyl-CoA dehydrogenases are reduced, a deficiency of electron-transferring flavoprotein, which serves as a hydrogen-acceptor for these dehydrogenases, is postulated as the underlying mechanisms of these two diseases, but a genetic heterogeneity was indicated by significant differences in the residual activities in these two types of cells. The hypothesis of more than one mutant allele of an autosomal recessive gene was also suggested by the study on cells from asymptomatic members of the family.

\section{INTRODUCTION}

We have recently described the case of ethylmalonicadipic aciduria who constantly excretes 2 -ethylmalonic acid, adipic acid, and $N$-hexanoylglycine in large amounts in urine (1). The major clinical symptoms of this patient are intermittent episodes of vomiting, lethargy, acidosis, and hypoglycemia. Hyperglycinuria is also occasionally observed. In the preliminary investigation, only a small amount of glutaric acid was occasionally detected. Inasmuch as the three major urinary metabolites are alternative metabolites of butyryl-CoA (1-3) and hexanoyl-CoA $(1,4)$, a genetic deficiency of butyryl-CoA dehydrogenase was postulated as a cause of this disease. These same metabolites have previously been detected in urine from patients with Jamaican vomiting sickness $(2,4,5)$ and a patient with glutaric aciduria type II (6). In contrast to the findings in the patient with ethylmalonic-adipic aciduria, however, large amounts of glutarate, isobutyrate, and isovalerate were detected in addition to ethylmalonate and adipate in urine of patients with these two previously known diseases. In particular, the amount of glutarate was very large in the patient with glutaric aciduria type II, exceeding by more than 10 times that of any other metabolite including ethylmalonate and adipate (6). Inhibition of several short- 
chain acyl-CoA dehydrogenases including glutarylCoA, butyryl-CoA, and isovaleryl-CoA dehydrogenases by an environmental toxin, hypoglycin (5), or by genetic mutation (6) has been proposed as the mechanism(s) of Jamaican vomiting sickness and glutaric aciduria type II, respectively. Only a single case of a neonate with the latter disease has been fully reported $^{1}(6)$.

We have subsequently carried out an extensive clinical investigation of our patient with ethylmalonicadipic aciduria including loading tests with medium chain triglycerides (MCT), ${ }^{2}$ lysine, and leucine to determine the metabolic pathways involved. In vitro experiments were also performed using cultured skin fibroblasts to further characterize the disease. Skin fibroblasts from the patient with glutaric aciduria type II were studied biochemically through comparing them to the present case. The results from these in vivo and in vitro investigations are described in this report.

\section{METHODS}

Patient. The proband is a white female born by breech delivery after a normal pregnancy to a 44-yr-old gravida 4, para 3 mother. $7 \mathrm{yr}$ before the patient was born, a female sibling had died on the 3rd d of life after a period of unexplained lethargy. Hepatomegaly with fatty infiltration of the liver was found at autopsy. Both parents and the two living male siblings are healthy, and there is no consanguinity in the family.

Symptoms were first noted at $7 \mathrm{wk}$ of age when, after a period of poor oral intake, she presented with a brief episode of tonic seizures (3-4 s). She recovered spontaneously and on evaluation a few hours later, was normal. A routine laboratory investigation was normal except for a mild elevation of serum lactic dehydrogenase $(263 \mathrm{U}$, normal $<255 \mathrm{U})$ and glutamic-oxaloacetic transaminase ( $300 \mathrm{U}$, normal $<50 \mathrm{U}$ ).

During the following $4 \mathrm{yr}$, the patient had two episodes of coma and convulsions associated with hypoglycemia and ketoacidosis. The first episode occurred at $1 \mathrm{yr}$ of age while she had mild gastroenteritis. She became increasingly lethargic and developed tonic seizures. She was admitted to a local hospital where moderate hypoglycemia $(30 \mathrm{mg} / \mathrm{dl})$ was found. Serum bicarbonate was $18 \mathrm{meq} / \mathrm{liter}$, glutamic-oxaloacetic transaminase $320 \mathrm{U}$, lactic dehydrogenase $446 \mathrm{U}$, and urine positive for ketones. Her sensorium gradually improved over several hours of supportive treatment. 2 mo later, at age $14 \mathrm{mo}$, she was admitted to the Yale Children's Clinical Research Center for evaluation of presumptive "ketotic hypoglycemia." However, a 24-h fast, ketogenic provocative diet, leucine tolerance test, intravenous glucose tolerance test, and glucagon stimulation all failed to elicit a response of blood glucose and insulin characteristic of this disorder or of other known diseases associated with infantile hypoglycemia.

At $4 \mathrm{yr}$ of age the second episode of vomiting, convul-

\footnotetext{
${ }^{1} \mathrm{~A}$ brief report of an additional case was presented by $\mathrm{L}$. Sweetman, T. A. Merrit, and W. L. Nyhan at the Annual Meeting of the American Society of Human Genetics, Vancouver, Canada, October 1978.

${ }^{2}$ Abbreviations used in this paper: ETF, electron transfer flavoprotein; MCT, medium-chain triglyceride(s).
}

sions, and coma with severe hypoglycemia (12 mg/dl) occurred. No precipitating factor was found at that time. She was again admitted to a local hospital. Blood urea nitrogen was $37 \mathrm{mg} / \mathrm{dl}$, serum bicarbonate $15 \mathrm{meq} / \mathrm{liter}$, blood ammonia $267 \mu \mathrm{g} / \mathrm{dl}$ (normal below $120 \mu \mathrm{g} / \mathrm{dl}$ ), and urine positive for ketones. Again glutamic-oxaloacetic transaminase and lactic dehydrogenase were slightly elevated, 119 and $323 \mathrm{U}$, respectively. She responded well to intravenous administration of $50 \%$ glucose. 2 mo later, urine screening for amino acids was done at the Yale-New Haven Hospital (Dr. M. R. Seashore) while she was clinically well. An excessive amount of glycine was detected. Plasma concentrations of glycine and alanine were also elevated with values of $422 \mu \mathrm{M}$ (normal $137-343$ ) and $486 \mu \mathrm{M}$ (normal 137-343), respectively, but those of other amino acids were within normal range. The unusual organic acids were subsequently identified by gas chromatography-mass spectrometric analysis (1).

Clinical investigation. At the age of $5 \mathrm{yr}$, the patient was again admitted to the Children's Clinical Research Center, Yale-New Haven Hospital for clinical investigation. On admission her weight was $20 \mathrm{~kg}$ (75th percentile), height $108 \mathrm{~cm}$ (50th percentile), head circumference $52 \mathrm{~cm}$ (50th percentile), and her physical examination was entirely normal. No signs of neurological damage or hepatomegaly were found. Her development was within normal range in all areas as assessed by the Revised Yale Developmental Schedule and the Stanford-Binet Scale.

Initially, she was put on a regular hospital diet for $6 \mathrm{~d}$ and consecutive 12 -h urines ( 8 a.m. -8 p.m. and 8 p.m. -8 a.m.) were collected during this period to obtain the basic level for organic acid excretion. Loading tests with three precursors (lysine, leucine, and medium chain triglycerides) were subsequently performed with parental consent at intervals of 3-4 d. Each loading test was done after overnight fasting. The amounts of precursors loaded are indicated in Results.

Analytical procedures. Urinary organic acids were analyzed as methyl esters by gas chromatography and the identification of the peaks was done by gas chromatography-mass spectrometry as previously described (7). Serum short-chain fatty acids were analyzed by gas chromatography using the method of Tanaka et al. (8). Urines were analyzed for short chain fatty acids after hydrolysis with barium hydroxide (7).

Urine screening for amino acids was done by one-way high voltage electrophoresis (9). A Beckman 119CL amino acid analyzer (Beckman Instruments, Inc., Fullerton, Calif.) was used to quantitate plasma amino acids after specimens were deproteinized with an equal volume of $10 \%$ sulfosalicylic acid. Serum carnitine was measured by the method of Marquis and Fritz (10).

Culture of skin fibroblasts. Skin biopsies were obtained from the proband, her parents, her two normal male siblings, and six normal subjects. All control lines except one were obtained from children younger than age 15 and most of them from children 5-10 yr old. Cultured skin fibroblasts from the original patient with glutaric aciduria type II (6) were the gift of Dr. H. J. Bremer, University Children's Hospital III, Düsseldorf, Germany. The fibroblasts were grown in Eagle's minimal essential medium (Grand Island Biological Co., Grand Island, N. Y.) supplemented with $10 \%$ bovine calf serum, nonessential amino acids and $2 \mathrm{mg} /$ liter kanamycin.

Substrate oxidation by cultured skin fibroblasts. The oxidation of the following four radioactive substrates was tested: $\left[1-{ }^{14} \mathrm{C}\right]$ butyrate, sodium salt (New England Nuclear, Boston, Mass.), $\left[2-{ }^{14} \mathrm{C}\right]$ lysine (ICN Nutritional Biochemicals, Cleveland, Ohio), [2-14 Clleucine (Schwarz/Mann Div., Becton, Dickinson \& Co., Orangeburg, N. Y.), and $\left[1-{ }^{14} \mathrm{C}\right]$ succinate (New England Nuclear). Monolayers of fibroblasts were 
washed with phosphate-buffered saline and trypsinized when confluent. The cells were suspended in Krebs-Ringer bicarbonate buffer pH 7.4, washed twice, and incubated with the radioactive substrate. The incubation was done in micro reaction vessels (Bolab, Inc., Derry, N. H.) at $37^{\circ} \mathrm{C}$ under $95 \%$ $\mathrm{O}_{2} 5 \% \mathrm{CO}_{2}$ atmosphere. The final incubation mixture was 50 $\mu 1$ containing $3-5 \times 10^{5}$ cells. The reaction vessels were vortexed every $10 \mathrm{~min}$ to avoid clumping of the cells and the reaction was stopped with $50 \mu \mathrm{l} 2 \mathrm{~N} \mathrm{H}_{2} \mathrm{SO}_{4}$. The radioactive $\mathrm{CO}_{2}$ released was collected into $200 \mu \mathrm{l} 1 \mathrm{M}$ hyamine hydroxide for $30 \mathrm{~min}$ during which the vials were vortexed every $5 \mathrm{~min}$ and then counted in a liquid scintillation spectrometer. The collection of ${ }^{14} \mathrm{CO}_{2}$ in the experiments with $\left[1-{ }^{14} \mathrm{C}\right]$ butyrate was done at $0^{\circ} \mathrm{C}$ to avoid evaporation of radioactive butyric acid from the incubation media.

Experiments with normal skin fibroblasts were done to determine the saturating substrate concentration and optimal incubation time for $\left[1-{ }^{14} \mathrm{C}\right]$ butyrate and $\left[2-{ }^{14} \mathrm{C}\right] \mathrm{lysine}$ with and without the addition of $3 \mathrm{mM}$.glucose into the incubation media. Similar experiments had been done previously with $\left[2-{ }^{14} \mathrm{C}\right]$ leucine by Tanaka et al. (11) and these conditions were used in our experiments. The experimental conditions used in this study are summarized in Table $I$. The addition of glucose as a possible primer was found to be unnecessary. Oxidation of each radioactive substrate by each cell line was tested several times (5-10 for the proband and 2-4 for the others) at different passages. All of the assays were done in triplicate.

Statistic analysis. The significance of the differences between the two groups of data was analyzed by the Student's $t$ test.

\section{RESULTS}

Urinary organic acids. Organic acid analysis of four random urine specimens collected at $4.5 \mathrm{yr}$ of age, when the child was clinically well, showed a constant excretion of 2-ethylmalonic acid, adipic acid, and hexanoylglycine (Fig. 1) in amounts ranging from 630 to 780 (normal: $3 \pm 2 \mathrm{SE}$ ), $210-740$ (normal: $2-9$ ), and 190-390 (normal: not detectable) $\mu \mathrm{g} / \mathrm{ml}$ creatinine, respectively, as described in the preliminary report (1). In two of these specimens, glutaric acid was detected in amounts of 80 and $240 \mu \mathrm{g} / \mathrm{mg}$ creatinine, but it was undetectable in two others. 2-Methylsuccinic acid was present in all four specimens in amounts $10-15 \%$ that of ethylmalonate, and small amounts of octanedioic

TABLE I

Experimental Conditions for the Oxidation of Various Radioactive Substrates by Cultured Skin Fibroblasts

\begin{tabular}{lcccc}
\hline Radioactive substrates & $\begin{array}{c}\text { Specific } \\
\text { activity }\end{array}$ & $\begin{array}{c}\text { Final } \\
\text { concen- } \\
\text { tration }\end{array}$ & $\begin{array}{c}\text { Incu- } \\
\text { bation } \\
\text { period } \\
\text { at } 37^{\circ} \mathrm{C}\end{array}$ & $\begin{array}{c}\text { Temperature } \\
\text { during }{ }^{14} \mathrm{CO}_{2} \\
\text { collection }\end{array}$ \\
\hline & $m \mathrm{Ci} / \mathrm{mmol}$ & $m M$ & $h$ & ${ }^{\circ} \mathrm{C}$ \\
{$\left[1-{ }^{14} \mathrm{C}\right]$ Butyrate } & 10.0 & 1 & 2 & 0 \\
{$\left[2-{ }^{14} \mathrm{C}\right]$ Lysine } & 1.1 & 5 & 3 & 37 \\
{$\left[2-{ }^{14} \mathrm{C}\right]$ Leucine } & 2.0 & 1 & 3 & 37 \\
{$\left[1,4-{ }^{14} \mathrm{C}\right]$ Succinate } & 2.0 & 1 & 3 & 37 \\
\hline
\end{tabular}

(suberic), decanedioic (sebacic), and decenedioic acids were also detected. 3-Hydroxybutyrate was not found.

Excretion of organic acids during the first $6 \mathrm{~d}$ of hospitalization are shown in Table II. Ethylmalonate, adipate, and hexanoylglycine were again the most prominent urinary metabolites; the amounts of ethylmalonate were somewhat smaller than those in the random urines collected at home. 2-Methylsuccinic acid was always present in amounts $2-10 \%$ that of ethylmalonate. Glutarate was excreted in small amounts during the 8 a.m. -8 p.m. period, but it was undetectable during the 8 p.m. -8 a.m. period. Such diurnal variation was not observed for other urinary organic acids.

Three random urine specimens were analyzed for short-chain fatty acids after hydrolysis with barium hydroxide. Hexanoic acid excretion was greatly increased (126-222 $\mu \mathrm{g} / \mathrm{mg}$ creatinine), whereas those of other short chain fatty acids were only moderately elevated (Table III).

Loading tests. Lysine monohydrochloride, one of the precursors of glutaryl-CoA, was given orally in a dose of $60 \mathrm{mg} / \mathrm{kg}$ three times a day for 2 consecutive $\mathrm{d}$ as had been described in the case of glutaric aciduria caused by deficiency of glutaconyl-CoA decarboxlase ${ }^{3}$ (12). With this loading, the urinary excretion of glutarate in our patient increased from 11 to only 70 and $111 \mu \mathrm{g} / \mathrm{ml}$ creatinine on the 1 st and $2 \mathrm{nd} \mathrm{d}$, respectively. The excretion of glutarate was increased during the 8 a.m. -8 p.m. period, whereas during the 8 p.m.8 a.m. interval glutarate was almost undetectable. No change was observed in her clinical condition during these two days with lysine loading.

Leucine, the precursor of isovaleryl-CoA, was administered orally in a single dose of $100 \mathrm{mg} / \mathrm{kg}$ as had been described for two patients with isovaleric acidemia (8). Urinary isovalerylglycine (15), which was undetectable before leucine administration, increased to $373 \mu \mathrm{g} / \mathrm{mg}$ creatinine during the first $12 \mathrm{~h}$ after leucine ingestion and fell to $82 \mu \mathrm{g} / \mathrm{mg}$ creatinine during the second $12 \mathrm{~h}$. Isovalerylglycine was not detectable on the $2 \mathrm{~d}$. Serum isovaleric acid was $120 \mu \mathrm{g} / 100 \mathrm{ml}$ before the leucine loading, and it rose to $1,200 \mu \mathrm{g} / 100$ $\mathrm{ml}$ at $2 \mathrm{~h}$ and fell to $440 \mu \mathrm{g} / 100 \mathrm{ml}$ at $4 \mathrm{~h}$.

MCT were given by mouth in one dose of $1.4 \mathrm{~g} / \mathrm{kg}$ as the precursor of butyryl-CoA. This dose was onethird the daily amount of MCT used in a ketogenic

\footnotetext{
${ }^{3}$ Activities of glutaryl-CoA dehydrogenation to glutaconylCoA and decarboxylation of the latter to crotonyl-CoA cannot be separated by biochemical means available at present (13). Glutaric aciduria is obviously a result of a genetic deficiency of glutaconyl-CoA decarboxylase activity judging from the metabolites that accumulate in patients with this disease (14), but it has been attributed to a deficiency of glutarylCoA dehydrogenase in some reports for this reason. Separate assays of these two enzyme activities in cells from patients with glutaric aciduria has not been achieved as yet.
} 


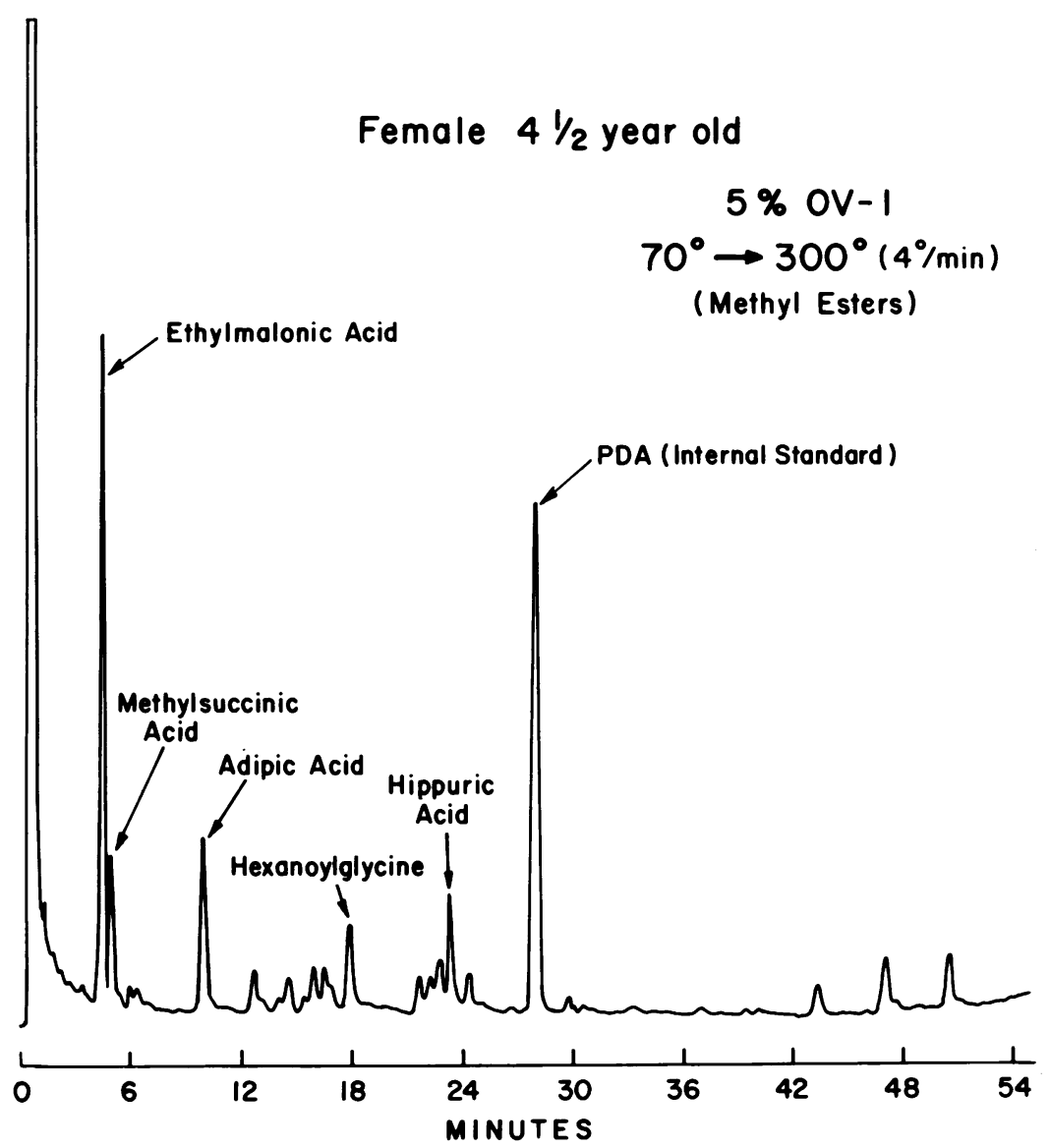

FIGURE 1 Gas chromatogram of urinary organic acids in the proband while she was on an ordinary family diet.

diet for treatment of intractable seizures (16). MCT feeding had a profound effect both on the clinical condition of the child and the urinary organic acids excreted. About $45 \mathrm{~min}$ after the ingestion of the MCT oil, the child started vomiting and became lethargic and pale. This episode of lethargy lasted for about 15 min, after which she appeared to have spontaneously regained consciousness for 10-15 min, but again she became lethargic. Because of this reaction, intravenous infusion of a glucose-electrolyte solution was started.

TABLE II

Urinary Excretion of Organic Acids by the Proband and Controls*

\begin{tabular}{|c|c|c|c|c|c|c|c|c|}
\hline \multirow[b]{2}{*}{ Metabolites } & \multicolumn{6}{|c|}{ Proband } & \multicolumn{2}{|c|}{$\begin{array}{c}\text { Four normal } \\
\text { children } 1\end{array}$} \\
\hline & Day 1 & Day 2 & Day 3 & Day 4 & Day 5 & Day 6 & Mean & SE \\
\hline & \multicolumn{8}{|c|}{$\mu g / m g$ creatinine } \\
\hline 2-Ethylmalonate & 351 & 170 & 191 & 387 & 385 & 333 & 3 & 1 \\
\hline 2-Methylsuccinate & 40 & 11 & 4 & 33 & 31 & 48 & 2 & 1 \\
\hline Glutarate & 30 & 19 & 15 & 18 & 20 & 14 & $\mathbf{0}$ & 0 \\
\hline Adipate & 848 & 1,320 & 470 & 219 & 176 & 498 & NDß & \\
\hline n-Hexanoylglycine & 183 & 45 & 201 & 159 & 224 & 247 & $N D \S$ & \\
\hline
\end{tabular}

* Each 24-h value was calculated from values of two corresponding 12-h urines.

\$ From Tanaka et al. (5).

$\$$ Not detectable by the present method. The amount of these compounds was too small to be positively identified and measured accurately. 
TABLE III

Urinary Short-chain Fatty Acids in the Proband and in Controls

\begin{tabular}{lrrrrrr}
\hline & \multicolumn{3}{c}{ Proband } & & \multicolumn{2}{c}{$\begin{array}{c}\text { Five normal } \\
\text { children* }\end{array}$} \\
\cline { 2 - 5 } \cline { 5 - 7 } Fatty acid & Urine 1 & Urine 2 & Urine 3 & & Mean & SE \\
\hline Propionic & 13 & 6 & 6 & & 6 & 5 \\
Isobutyric & 35 & 19 & 21 & & 1 & 0.4 \\
Butyric & 20 & 8 & 12 & & 1 & 0.3 \\
Isovaleric & 20 & 7 & 14 & & 4 & 1.8 \\
Crotonic & 9 & 5 & 6 & & 0 & \\
Hexanoic & 222 & 126 & 146 & & 0 & \\
\hline
\end{tabular}

${ }^{*}$ From Tanaka et al. (5).

Blood glucose, electrolytes, and blood ammonia at this point were normal. These episodes of intermittent lethargy were repeated two to three times and the child gradually recovered over a 2 -h period. There was a marked increase of ethylmalonate excretion during the first $6 \mathrm{~h}$ (Table IV). Methylsuccinate, adipate, hexanoylglycine, and dicarboxylic acids with 8-10 carbons were also increased following the test. Urinary glutarate also increased although MCT is not a precursor of glutarate. No significant increase of 3-hydroxybutyrate was detected. Analysis of serum short chain fatty acids disclosed high fasting concentrations of butyric and hexanoic acids. These values are 8 and 29 times higher than control values, respectively. The elevations of serum propionic and isovaleric acids were much less pronounced. Serum levels of butyric and hexanoic acids greatly increased to 1,220 and $3,710 \mu \mathrm{g} / 100 \mathrm{ml}$, respectively, at $6 \mathrm{~h}$. Crotonic acid was not detectable at any time (Table V).

Subsequent course and effects of low fat diet. $1 \mathrm{wk}$ after the patient had been discharged from the Clinical

TABLE IV

Excretion of Urinary Organic Acids after Loading with $M C T^{*}$

\begin{tabular}{lrrrr}
\hline & \multicolumn{4}{c}{ Concentrations in urine } \\
\cline { 3 - 5 } \multicolumn{1}{c}{ Organic acids } & hours $\ldots .12-0$ & $0-6$ & $6-12$ & $12-24$ \\
\hline & \multicolumn{4}{c}{$\mu g / m g$ creatinine } \\
2-Ethylmalonate & 283 & 6,300 & 479 & 280 \\
2-Methylsuccinate & 19 & 145 & 38 & 21 \\
Glutarate & 0 & 885 & 136 & trace \\
Adipate & 828 & 602 & 223 & 134 \\
Suberate & 24 & 569 & 103 & trace \\
Sebacate & trace & 1,290 & 517 & trace \\
Hexanoylglycine & 344 & 291 & trace & 197 \\
\hline
\end{tabular}

* A single dose $(1.4 \mathrm{~g} / \mathrm{kg})$.
TABLE V

Serum Short-chain Fatty Acid Concentrations after Loading with MCT

\begin{tabular}{lrcr}
\hline & \multicolumn{3}{c}{ Serum concentrations } \\
\cline { 2 - 4 } Compound & Fasting & At 3 h & At 6 h \\
\hline & & $\mu g / 100 \mathrm{ml}$ & \\
Propionic & 71 & 44 & 48 \\
Isovaleric & 114 & 409 & 199 \\
Butyric & 96 & 1,220 & 346 \\
Hexanoic & 461 & 3,710 & 1,470 \\
Crotonic & - & - & - \\
\hline
\end{tabular}

Research Center, she was readmitted because of vomiting and lethargy during an upper respiratory infection. During the first $4 \mathrm{~h}$ after admission, the most prominent organic acid excreted was adipate $(1,830$ $\mu \mathrm{g} / \mathrm{ml}$ creatinine) followed by glutarate $(811 \mu \mathrm{g} / \mathrm{mg}$ creatinine). Only a trace amount of ethylmalonate was found during this period. The excretion of glutarate dropped to an undetectable level at $12 \mathrm{~h}$, while that of ethylmalonate increased to $218 \mu \mathrm{g} / \mathrm{mg}$ creatinine.

After discharge, she was given a diet relatively low in fat and high in carbohydrates. The approximate caloric composition of the diet was $20 \%$ from fats, $65 \%$ from carbohydrates, and $15 \%$ from proteins. Urinary organic acids were analyzed on 12 consecutive 24 -h urines during this period. In general, the amounts of total urinary organic acids were greatly reduced. In most of the urines, the amount of ethylmalonic acid was by far the largest except on $2 \mathrm{~d}$ when the amount of adipate exceeded that of ethylmalonate. Glutarate was detected in small amounts in only two urines (Table VI).

During a 16-mo period, while she was on the low fathigh carbohydrate diet, she developed four mild episodes of vomiting and lethargy. One of these episodes occurred while she had an upper respiratory infection. The triggering factor in the other three episodes is not clear. In none of these episodes did she become hypoglycemic or acidotic.

Serum carnitine levels. Serum carnitine levels were assayed on two occasions. The two values were 50 and $51 \mathrm{nmol} / \mathrm{ml}$ and were within normal range.

Oxidation in vitro of $\left[1-{ }^{14} \mathrm{C}\right]$ butyrate, $\left[2-{ }^{14} \mathrm{C}\right]$ lysine, $\left[2-{ }^{14} \mathrm{C}\right]$ leucine, and $\left[1,4-{ }^{14} \mathrm{C}\right]$ succinate by cultured skin fibroblasts. The mean ${ }^{14} \mathrm{CO}_{2}$ production from [1${ }^{14} \mathrm{C}$ ]butyrate by the patient's cells in assays done on 10 different occasions was $14 \%$ that of the mean of the controls. The impairment of $\left[1-{ }^{14} \mathrm{C}\right]$ butyrate oxidation was not restored by addition of $1-5 \mathrm{mM}(-)$ carnitine to the assay media. More severe impairment of butyrate oxidation is observed with the cells of the patient with glutaric aciduria type II. The mean amount of ${ }^{14} \mathrm{CO}_{2}$ produced by these cells was only three percent of the 
TABLE VI

Urinary Organic Acids while the Patient Was on Low Fat-high Carbohydrate Diet

\begin{tabular}{|c|c|c|c|}
\hline Days & 2-Ethylmalonate & Glutarate & Adipate \\
\hline & \multicolumn{3}{|c|}{$\mu g / m g$ creatinine } \\
\hline 1 & 69 & $0 \S$ & $0 \S$ \\
\hline 2 & 1,040 & $0 \S$ & 2,050 \\
\hline 3 & 30 & $0 \$$ & 150 \\
\hline 4 & 43 & $0 \S$ & 15 \\
\hline $5^{*}$ & 240 & $0 \S$ & 50 \\
\hline 6 & 425 & $0 \$$ & 30 \\
\hline $7 * \ddagger$ & 270 & $0 \$$ & 13 \\
\hline 8 & 182 & $0 \$$ & 0 \\
\hline 9 & 265 & 27 & 40 \\
\hline $10^{*}$ & 1,180 & 20 & 73 \\
\hline $11^{*}$ & 149 & $0 \$$ & 10 \\
\hline $12 * \ddagger$ & 102 & $0 \$$ & 10 \\
\hline
\end{tabular}

In these urines, hexanoylglycine was generally not detectable.

* Urines contained significant amounts of sebacate.

\$ Urines contained hexanoylglycine in small amounts.

$\S$ Not detectable at the sensitivity used in these analyses.

mean of the controls. This value was significantly lower than that for the proband cells $(P<0.001)$ (Table VII).

The ${ }^{14} \mathrm{CO}_{2}$ production from $\left[2-{ }^{14} \mathrm{C}\right]$ lysine by the proband's cells was $28 \%$ of the mean of controls. Again the oxidation of lysine was more severely impaired in glutaric aciduria type II cells. It was $9 \%$ that of the mean of controls (Table VII).

The ${ }^{14} \mathrm{CO}_{2}$ production from $\left[2-{ }^{14} \mathrm{C}\right]$ leucine by the proband cells was $23 \%$ of the mean of controls. In glutaric aciduria type II, leucine oxidation was more severely impaired, and it was only $9 \%$ of the mean of controls (Table VII).

The ${ }^{14} \mathrm{CO}_{2}$ production from succinate by fibroblasts from the proband and the patient with glutaric aciduria type II was within the normal range (Table VII). Therefore, the impairment of oxidation of butyrate, lysine, and leucine in cells from our patient and those from the patient with glutaric aciduria type II is not caused by a decreased viability of the cells.

$\left[1-{ }^{14} \mathrm{C}\right]$ Butyrate oxidation activity of the mother's cells was the highest among those of family members, but it was about $40 \%$ of the mean of control values and significantly lower than the lowest control value (Table VIII). The same activity of the cells from the father and the older sibling was somewhat lower than that of the mother's cells, but it was significantly higher than that of the proband $(P<0.01)$. The activity of cells from the other sibling was lower than that of other family members (excluding the proband) and it was only 1.6 times higher than that of the proband. The ability of cells from family members to oxidize [1,4${ }^{14} \mathrm{C}$ ]succinate was within the normal range (Table VIII).

Because of the low level of $\left[1-{ }^{14} \mathrm{C}\right]$ butyrate oxidation, at least three urines from each family member were analyzed for organic acids. In none of the urines was ethylmalonate, glutarate, adipate or hexanoylglycine detected in signilficant amounts.

\section{DISCUSSION}

The most prominent biochemical finding in the present case was the excretion of large amounts of 2-ethyl-

TABLE VII

Oxidation of $\left[1-{ }^{14} \mathrm{C}\right]$ Butyrate, $\left[2-{ }^{14} \mathrm{C}\right]$ Lysine, $\left[2-{ }^{14} \mathrm{C}\right]$ Leucine, and $\left[1,4-{ }^{14} \mathrm{C}\right]$ Succinate by Cultured Skin Fibroblasts

\begin{tabular}{|c|c|c|c|c|}
\hline \multirow[b]{2}{*}{ Cells } & \multicolumn{4}{|c|}{ Substrates } \\
\hline & {$\left[1-{ }^{14} \mathrm{C}\right]$ Butyrate } & {$\left[2-{ }^{14} \mathrm{C}\right]$ Lysine } & {$\left[2-{ }^{14} \mathrm{C}\right]$ Leucine } & {$\left[1,4^{-14} \mathrm{C}\right]$ Succinate } \\
\hline & \multicolumn{4}{|c|}{ nmol ${ }^{4} \mathrm{CO}_{2}$ produced $/ 10^{8}$ cells $/ \mathrm{h}$} \\
\hline Control 1 & $1.86 \pm 0.13$ & $0.37 \pm 0.04$ & $0.45 \pm 0.00^{*}$ & $0.57 \pm 0.07^{*}$ \\
\hline Control 2 & $3.13 \pm 0.33$ & $0.62 \pm 0.22^{*}$ & $0.61 \pm 0.18^{*}$ & $0.58 \pm 0.01^{*}$ \\
\hline Control 3 & $4.07 \pm 0.82$ & $0.71 \pm 0.09^{*}$ & $0.45 \pm 0.06^{*}$ & $1.15 \pm 0.33^{*}$ \\
\hline Control 4 & $1.97 \pm 0.00^{*}$ & $0.74 \pm 0.08^{*}$ & $0.53 \pm 0.08^{*}$ & $1.64 \pm 0.10^{*}$ \\
\hline Control 5 & $1.46 \pm 0.14$ & $0.47 \pm 0.05$ & $0.40 \pm 0.23^{*}$ & $0.45 \pm 0.14^{*}$ \\
\hline Control 6 & $2.99 \pm 0.18$ & $0.27 \pm 0.03$ & $0.41 \pm 0.14^{*}$ & $0.92 \pm 0.18^{*}$ \\
\hline Mean of six controls & $2.57 \pm 0.39$ & $0.53 \pm 0.08$ & $0.47 \pm 0.03$ & $0.89 \pm 0.20$ \\
\hline Proband & $0.35 \ddagger \pm 0.04$ & $0.15 \ddagger \pm 0.03$ & $0.11 \downarrow \pm 0.04$ & $0.89 \pm 0.18$ \\
\hline Glutaric aciduria type II & $0.08 \ddagger \pm 0.00^{*}$ & $0.05 \ddagger \pm 0.00^{*}$ & $0.04 \ddagger \pm 0.00^{*}$ & $0.91 \pm 0.31^{*}$ \\
\hline $\begin{array}{l}P \text { values for the difference between the } \\
\text { proband and glutaric acidemia type II cells }\end{array}$ & $<0.001$ & $<0.02$ & $>0.05$ & \\
\hline
\end{tabular}

Data are expressed as mean $\pm \mathrm{SE}$ unless otherwise mentioned.

* Mean of two experiments \pm difference from the mean.

‡ Significantly different from control $(P<0.001)$. 
TABLE VIII

Oxidation of $\left[1-{ }^{14} \mathrm{C}\right]$ Butyrate and $\left[1,4-{ }^{14} \mathrm{C}\right]$ Succinate by Cultured Skin Fibroblasts from Family Members

\begin{tabular}{|c|c|c|}
\hline \multirow[b]{2}{*}{ Cell lines } & \multicolumn{2}{|c|}{ Substrates } \\
\hline & {$\left[1-{ }^{14} \mathrm{C}\right]$ Butyrate } & {$\left[1,4-{ }^{14} \mathrm{C}\right]$ Succinate } \\
\hline & \multicolumn{2}{|c|}{ nmol/10 cells/h } \\
\hline Father & $0.72 * \pm 0.04$ & $1.04 \pm 0.23$ \\
\hline Mother & $1.06^{*} \pm 0.22$ & $1.05 \pm 0.23$ \\
\hline Sibling I (male, 13 yr) & $0.87^{*} \pm 0.13$ & $1.30 \pm 0.12$ \\
\hline Sibling II (male, $11 \mathrm{yr}$ ) & $0.57 \ddagger \pm 0.09$ & $1.24 \pm 0.29$ \\
\hline
\end{tabular}

Results are expressed as mean of three or four experiments \pm SE. Each experiment was done in triplicate.

* Significantly different from control $(P<0.01$.

† Significantly different from control $(P<0.001)$.

malonic acid, adipic acid, and hexanoylglycine. Although several other organic acids were also excreted occasionally in increased amounts, these three metabolites were always excreted in the largest amounts. The constant excretion of these abnormal metabolites together with the history of neonatal death of a sibling after a period of lethargy are strongly suggestive of an inborn error of metabolism.

Ethylmalonic acid, adipic acid, and hexanoylglycine are metabolically interrelated and must be considered as one group distinct from the other metabolites for the following reasons. Two mechanisms had previously been proposed for ethylmalonate biosynthesis, namely the carboxylation of butyryl-CoA by propionyl-CoA carboxylase (17), and the oxidation of 2-ethylhydracrylic acid (2-ethyl, 3-hydroxypropionic acid) in the R-pathway of isoleucine (18). More recently, however, we have shown in rats in vivo using precursors labeled with ${ }^{13} \mathrm{C}$ and ${ }^{2} \mathrm{H}$ at various positions that butyrate can, in fact, be incorporated into urinary ethylmalonate, and that 2-ethylhydroacrylic acid is, for the most part (98\%), first converted to butyryl-CoA and then carboxylated (3). Therefore, the carboxylation of butyryl-CoA is actually the only major mechanism for ethylmalonate synthesis. Adipic acid and hexanoylglycine, on the other hand, are both known to be formed from hexanoic acid, the former by $\omega$-oxidation (19) and the latter by conjugation with glycine (4) (Fig. 2). Thus, the three major abnormal metabolites in this patient appear to have been derived from butyric and hexanoic acids, indicating that the patient had a block in $\beta$ oxidation of fatty acids at the stages of butyryl-CoA and hexanoyl-CoA. These observations led us previously to propose a deficiency of butyryl-CoA dehydrogenase activity as a mechanism of this disease (1). This hypothesis is further supported in the present study by reduced ability of cultured cells from the proband to oxidize $\left[1{ }^{14} \mathrm{C}\right]$ butyrate and also by evidence from the MCT loading test that resulted in a massive urinary excretion of ethylmalonate and marked elevation of butyric and hexanoic acids in blood. These biochemical changes were accompanied by severe transient vomit-

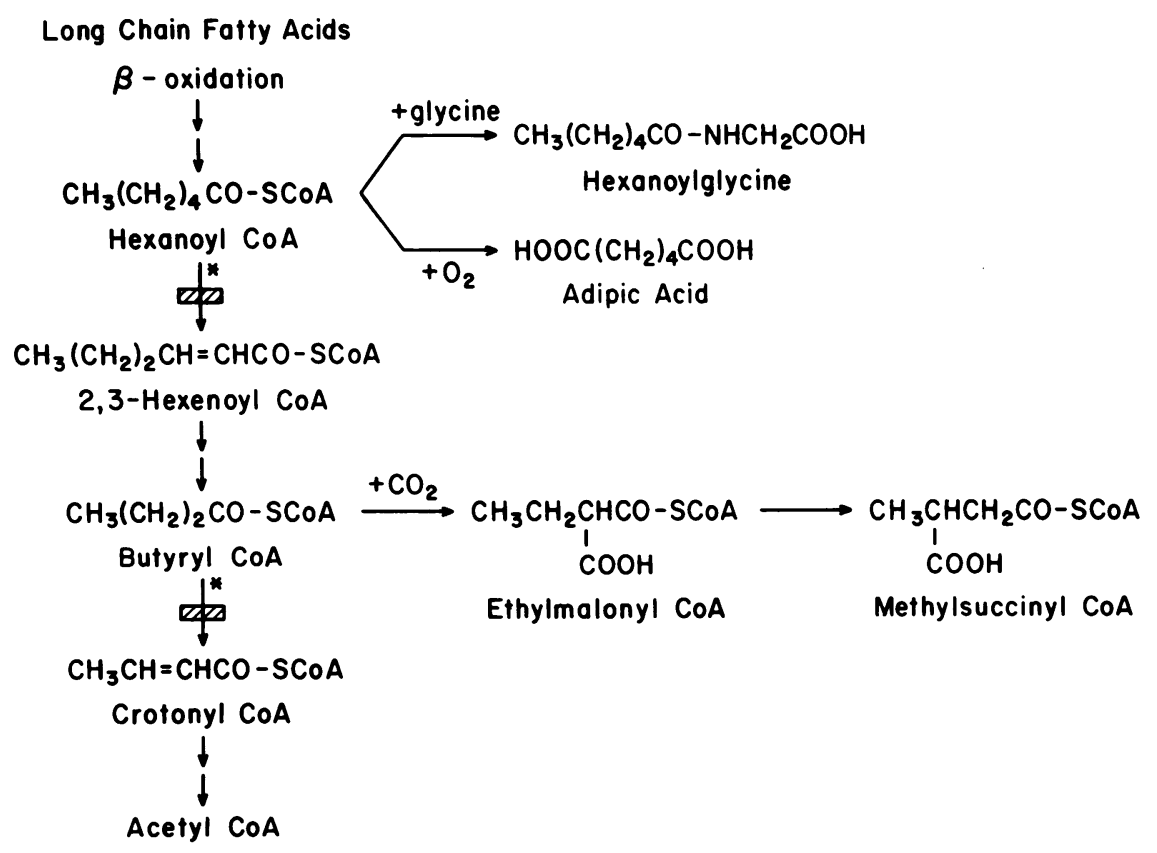

FIGURE 2 Altered metabolism of fatty acids in the proband. The vertical central portion illustrates normal fatty acid metabolism. The metabolic blocks are shown as shaded rectangles. Horizontal arrows indicate altered metabolism in the proband. 
ing and lethargy. Crotonic acid and 3-hydroxybutyrate, which are the metabolites immediately following butyryl CoA dehydrogenation, were not detected at all in the patient's blood or urine before and after the loading.

It was important to determine whether pathways other than that of fatty acid oxidation were blocked in the present case as in the case of glutaric aciduria type II, although the spectrum of urinary metabolites was more consistent with a specific deficiency of butyrylCoA dehydrogenase activity. The results from in vitro experiments using cultured skin fibroblasts are rather unexpected in this regard. The abilities of the proband's cells to oxidize both $\left[2-{ }^{14} \mathrm{C}\right]$ lysine and $\left[2-{ }^{14} \mathrm{C}\right]-$ leucine were reduced, representing 28 and $23 \%$ of the mean of controls, respectively, although not as much as their ability to oxidize $\left[1-{ }^{14} \mathrm{C}\right]$ butyrate $(14 \%$ of the mean of controls). We also tested cells from the patient with glutaric aciduria type II for these activities. The abilities of glutaric aciduria type II cells to oxidize $\left[1-{ }^{14} \mathrm{C}\right]$ butyrate, $\left[2-{ }^{14} \mathrm{C}\right]$ lysine, and $\left[2-{ }^{-14} \mathrm{C}\right]$ leucine were 3,9 , and $9 \%$ of the mean of controls, respectively. These activities were much lower than those seen in our proband's cells but the pattern of deficiencies was similar. Thus, the results from in vitro studies as well as those from metabolite analyses indicate that several catabolic pathways including those for fatty acids, lysine, and leucine are blocked at the stage of short-chain acylCoA dehydrogenases in these diseases (Fig. 3). It has been shown that several specific acyl-CoA dehydrogenases exist for each individual short-chain acylCoA $(8,13)$. Therefore, a deficiency of activities of multiple acyl-CoA dehydrogenases in ethylmalonicadipic aciduria and glutaric aciduria type II are probably not caused by a mutation of genes for acyl-CoA dehydrogenases, but rather we postulate mutation of a gene for a protein component that is commonly shared by these acyl-CoA dehydrogenases as part of

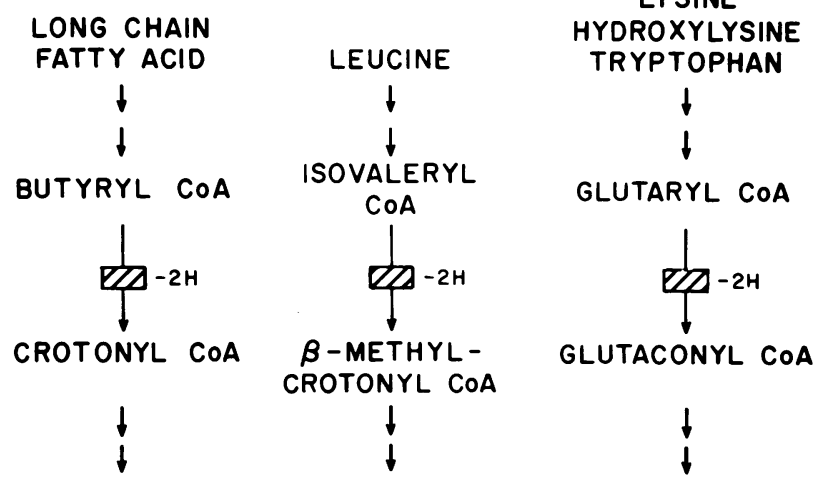

FIGURE 3 Illustration of the deficiency of activities of multiple acyl-CoA dehydrogenases in the patients with ethylmalonic aciduria and glutaric aciduria type II. their structure or, alternatively, a protein which is commonly required for the activity of these enzymes. Since there is no evidence for common subunit structure in these acyl-CoA dehydrogenases (20), the latter possibility is more likely. This conclusion is supported by our recent experimental results that activities of mitochondrial butyryl-CoA dehydrogenase and isovaleryl-CoA dehydrogenase were both normal in ethylmalonic acidemia cells and glutaric aciduria type II cells (21). It is known that these acyl-CoA dehydrogenases require electron transfer flavoprotein (ETF) as the acceptor of hydrogens subtracted from the substrate (Fig. 4). There is evidence for a single ETF serving more than one dehydrogenase (22). It is tempting to speculate that ethylmalonic-adipic aciduria and glutaric aciduria type II are both caused by a mutation of a gene coding for ETF. The increase of urinary glutarate after MCT loading in our patient may be explained by competition of butyryl-CoA and glutarylCoA dehydrogenases for a deficient ETF activity. These observations indicate that the present phenotypical nomenclature of these diseases is inappropriate, causing misunderstanding of the nature of these diseases. It is desirable to rename them according to the nature of the deficient enzyme activity, but it must be deferred until such deficiency is pinpointed in the future using more sensitive, specific assays such as those recently developed for the study of isovaleric acidemia (23).

Although the mutation of the same gene is indicated for the etiology of ethylmalonic aciduria and glutaric aciduria type II, a genetic heterogeneity of these two diseases was evident inasmuch as the degrees of deficient activities for butyrate oxidation of these two cell lines were significantly different $(P<0.001)$. The hypothesis of more than one mutant allele may also explain the results of the family study. The ability of cells from the father and mother to oxidize $\left[1-{ }^{14} \mathrm{C}\right]-$ butyrate were lower than the lowest normal value and were 28 and $41 \%$ of the mean of controls, respectively, but their values are significantly higher than that of the proband $(P<0.001)$. This suggests that they are both heterozygotes. The same activity of the cells from two asymptomatic siblings is also low; 34 and $22 \%$ of the mean of controls, respectively. The value for the second sibling was significantly higher than that for the proband but considerably lower than that for any other asymptomatic family member. These data on the proband and the asymptomatic family members do not fit well to the simple Mendelian pattern if we assume a

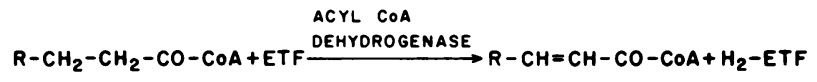

Figure 4 A general scheme for the mode of action of acylCoA dehydrogenases. 
single mutant allele, but these may well be explained by assuming that the father and mother each have different mutant alleles of differing severity and that the proband is a genetic compound for these alleles rather than a homozygote for a single mutant allele. This hypothesis, however, must be further tested with more sensitive, specific assay methods.

Marked differences also exist between ethylmalonic aciduria and glutaric aciduria type II in clinical severity and metabolite pattern. In glutaric aciduria type II, the amount of glutarate was overwhelmingly large. The increase of ethylmalonic acid was about $1 / 18$ that of glutarate, and was similar to that of urinary ethylmalonate in our patient. The patient with glutaric aciduria type II became severely acidotic immediately after birth and died at the age of $70 \mathrm{~h}$. In the present case, the amount of glutarate was relatively large only on one occasion when she had a severe acidotic episode. In contrast, the amount of ethylmalonate remained high while the patient was on a low-fat diet but glutarate was usually undetectable during this period.

We performed loading tests on our patient with lysine and leucine in addition to that with MCT to characterize her disease clinically. Pronounced increases in serum isovaleric acid and urinary isovalerylglycine were observed after leucine loading in our patient, but the increase in serum isovaleric acid was $15-50 \%$ of that seen in patients with isovaleric acidemia (8). In spite of the reduced capacity to oxidize $\left[2-{ }^{14} \mathrm{C}\right]$ lysine in vitro, lysine loading resulted in only a transient increase in glutarate that was much smaller $(2 \%)$ than that observed in a patient with glutaric aciduria after loading the same amount of lysine (12). The molecular basis for predominance of ethylmalonate and minor increase of glutarate even after lysine loading in our patient is yet to be elucidated.

In addition to the major metabolites, several other organic acids, were excreted in increased amounts by this patient. These include 2-methylsuccinic acid, and dicarboxylic acids with 8 and 10 carbons. Among them the most constant finding was the excretion of methylsuccinic acid in amounts about $10 \%$ of ethylmalonic acid. Since this ratio is very constant, this acid is probably produced by isomerization of ethylmalonylCoA as has been shown in a bacterial system (24) (Fig. 2 ). The formation of dicarboxylic acids with 8 and 10 carbons can be explained by $\omega$-oxidation of the corresponding monocarboxylic acids (19).

An occasional medium-chain dicarboxylic aciduria consisting of adipate, suberate, and sebacate has been observed in a patient with a systemic carnitine deficiency (25). This disease is characterized by lipid storage myopathy and recurrent episodes of hypoglycemia (26). Unlike the present patient, however, neither ethylmalonate nor hexanoylglycine was detected (25), indicating that butyrate and hexanoate oxidation is not inhibited in the patient with carnitine deficiency. This finding is consistent with the knowledge that carnitine is not required for mitochondrial butyrate and hexanoate oxidation (27). Adipate and dicarboxylic acids with 8 and 10 carbons may alternatively be produced by $\beta$-oxidation of dicarboxylic acids with longer chains, which are produced from longchain fatty acids as a result of carnitine deficiency. Normal serum carnitine concentration and lack of myopathy in our patient also indicates that the metabolic derangement in our patient is not caused by carnitine deficiency. Addition of (-)carnitine to incubation media did not restore $\left[1-{ }^{14} \mathrm{C}\right]$ butyrate oxidation by our proband's cells.

The biochemical mechanism for episodic hypoglycemia seen in this patient may be readily explained by the present knowledge of metabolic regulation. It has been shown that 2-alkyl-substituted malonic acids, such as methylmalonic acid and butylmalonic acid, strongly inhibit mitochondrial malate transport, which is a rate-limiting step in the early phase of gluconeogenesis $(28,29)$. Therefore, during periods of poor oral intake and catabolic stress because of infections, an inhibition of the malate transport by a high intracellular concentration of ethylmalonate would result in suppression of gluconeogenesis and consequent hypoglycemia. The inhibition of overall fatty acid oxidation is also a contributing factor to the inhibition of gluconeogenesis as has been shown previously $(29,30)$.

\section{ACKNOWLEDGMENTS}

We thank Doctors S. J. Danoff and R. L. Zimmern and their associates for referring this patient and for their help in the clinical management, Ms. Beatrice Billings and Ms. Agnes Dull for gas chromatographic analysis, and Messrs. Bruce Baretz and Jonathan Amster of our laboratory for mass spectral analysis. We are also indebted to Dr. Huntington Willard for discussions on genetic mechanisms, Mr. Edward Currey for measuring the serum carnitine levels and Dr. Gail Landy for the development evaluation of this patient.

This study was supported in part by a National FoundationMarch of Dimes grant (1-378) and U. S. Public Health Service grants (AM-17453 and GM-07439). Clinical investigation was performed in the Yale Children's Clinical Research Center and was supported by a grant (RR-125) from the National Institutes of Health.

\section{REFERENCES}

1. Tanaka, K., S. Mantagos, M. Genel, M. R. Seashore, B. A. Billings, and B. H. Baretz. 1977. New defect in fatty acid metabolism with hypoglycemia and organic aciduria. Lancet. II: 986-987.

2. Tanaka, K., H. S. Ramsdell, B. H. Baretz, M. B. Keefe, E. A. Kean, and B. Johnson. 1976. Identification of ethylmalonic acid in urine of two patients with the vomiting sickness of Jamaica. Clin. Chim. Acta. 69: 105-112.

3. Baretz, B. H., C. P. Lollo, and K. Tanaka. 1979. Metabolism in rats in vivo of RS-2-methylbutyrate and nbutyrate labelled with stable isotopes at various positions: 
mechanism of biosynthesis and degradation of ethylmalonyl semialdehyde and ethylmalonic acid. J. Biol. Chem. 254: 3468-3478.

4. Baretz, B. H., H. S. Ramsdell, and K. Tanaka. 1976. Identification of $n$-hexanoylglycine in urines from two patients with Jamaican vomiting sickness. Clin. Chim. Acta. 73: 199-202.

5. Tanaka, K., E. A. Kean, and B. Johnson. 1976. Jamaican vomiting sickness. Biochemical investigation of two cases. N. Engl. J. Med. 295: 461-467.

6. Przyrembel, H., U. Wendel, K. Becker, H. J. Bremer, L. Bruinvis, D. Ketting, and S. K. Wadman. 1976. Glutaric aciduria type II: Report of a previously undescribed metabolic disorder. Clin. Chim. Acta. 66: 227-239.

7. Tanaka, K. 1972. Mode of action of hypoglycin A (III): isolation and identification of cis-4-decene-1,10-dioate, cis,-cis-4,7-decadiene-1,10-dioate, cis-4-octene-1,8dioate, glutarate, adipate, $N$-(methylenecyclopropyl)acetylglycine, and $\mathrm{N}$-isovalerylglycine from urine of hypoglycin A-treated rats. J. Biol. Chem. 247: 7465-7478.

8. Tanaka, K., M. A. Budd, M. L. Efron, and K. J. Isselbacher. 1966. Isovaleric acidemia: a new genetic defect of leucine metabolism. Proc. Natl. Acad. Sci. U. S. A. 56: 236-242.

9. Shih, V. E. 1973. Laboratory techniques for the detection of hereditary metabolic disorders. CRC Press, Inc., Cleveland. 16-24.

10. Marquis, N., and I. Fritz. 1964. Enzymological determination of free carnitine concentrations in rat tissues. $J$. Lipid Res. 5: 184-187.

11. Tanaka, K., R. Mandell, and V. E. Shih. 1976. Metabolism of $\left[1-{ }^{14} \mathrm{C}\right]$ and $\left[2-{ }^{14} \mathrm{C}\right]$ leucine in cultured skin fibroblasts from patients with isovaleric acidemia. Characterization of metabolic defect. J. Clin. Invest. 58: 164-172.

12. Goodman, S., S. Markey, P. Moe, B. Miles, and C. Teng. 1975. Glutaric aciduria: a new disorder of amino acid metabolism. Biochem. Med. 12: 12-21.

13. Besrat, A., C. E. Polan, and L. M. Anderson. 1969. Mammalian metabolism of glutaric acid. J. Biol. Chem. 244: 1461-1467.

14. Stokke, O., S. I. Goodman, J. Thompson, and B. Miles. 1975. Glutaric aciduria: Presence of glutaconic and $\beta$ hydroxyglutaric acids in urine. Biochem. Med. 12: 386-391.

15. Tanaka, K., and K. J. Isselbacher. 1967. The isolation and identification of $\mathrm{N}$-isovalerylglycine from urine of patients with isovaleric acidemia. J. Biol. Chem. 242: 2966-2972.

16. Signore, J. M. 1973. Ketogenic diet containing medium chain triglycerides. J. Am. Diet. Assoc. 62: 285-290.
17. Hegre, C. S., D. K. Halenz, and M. D. Lane. 1959. The enzymatic carboxylation of butyryl coenzyme A. J. Am. Chem. Soc. 81: 6526-6527.

18. Mamer, O. A., S. S. Tjoa, C. R. Scriver, and G. A. Klassen. 1976. Demonstration of a new mammalian isoleucine catabolic pathway yielding an $\mathrm{R}$ series of metabolites. Biochem. J. 160: 417-426.

19. Wakabayashi, K., and N. Shimazono. 1963. Studies on $\omega-$ oxidation of fatty acids in vitro. I. Overall reaction and intermediate. Biochim. Biophys. Acta. 70: 132-142.

20. Hall, C. L., and H. Kamin. 1975. The purification and some properties of electron transfer flavoprotein and general fatty acyl coenzyme A dehydrogenase from pig liver mitochondria. J. Biol. Chem. 250: 3476-3486.

21. Rhead, W., and K. Tanaka. 1979. Evidence for normal isovaleryl and butyryl CoA dehydrogenase activity in fibroblast mitochondria from patients with glutaric aciduria type II. Am. J. Hum. Genet. 31: 59A. (Abstr.)

22. Hoskins, D. D. 1966. The electron-transferring flavoprotein as a common intermediate in the mitochondrial oxidation of butyryl coenzyme A and sarcosine. J. Biol. Chem. 241: 4472-4478.

23. Rhead, W., and K. Tanaka. 1979. Development of a tritium release assay for isovaleryl CoA dehydrogenase and characterization of this enzyme in rat liver mitochondria. Fed. Proc. 38: 648. (Abstr.)

24. Retey, J., E. Smith, and B. Zagalak. 1978. Investigation of the mechanism of the methylmalonyl-CoA mutase reaction with the substrate analogue: ethylmalonyl-CoA. Eur. J. Biochem. 83: 437-451.

25. Karpati, G., S. Carpenter, A. Engel, G. Watters, J. Allen, S. Rothman, G. Klassen, and O. Mamer. 1975. The syndrome of systemic carnitine deficiency. Neurology. 25: 16-24.

26. Engel, A. G., and C. Angelini. 1973. Carnitine deficiency of human skeletal muscle with associated lipid storage myopathy: a new syndrome. Science (Wash. D. C.). 179: 899-901.

27. Fritz, I. B., E. Kaplan, and K. T. N. Yue. 1962. Specificity of carnitine action on fatty acid oxidation by heart muscle. Am. J. Physiol. 202: 117-121.

28. Chappel, J. B. 1968. Systems used for the transport of substrates into mitochondria. Br. Med. Bull. 24: 150-157.

29. Tanaka, K. 1975. Disorders of organic acid metabolism. Biol. Brain Dysfunct. 3: 145-214.

30. Söling, H. D., B. Willms, D. Friedrichs, and J. Kleinecke. 1962. Regulation of gluconeogenesis by fatty acid oxidation in isolated perfused livers of non-starved rats. Eur. J. Biochem. 4: 364-372. 